\title{
IOT Based Vehicle Tracking and Monitoring System Using GPS and GSM
}

\author{
A. Mounika, Anitha Chepuru
}

\begin{abstract}
Generally the usage of vehicle tracking system has been increased rapidly. The major concern of the proposed system is identifying the vehicle theft by implementing anti-system. Vehicle tracking system is bene-ficial in many ways such as providing security to the personal vehicles, taxis, cabs, school buses/cars and others. Vehicle tracking system is designed to know the position of the vehicle. Tracking system is developed by using GPS and GSM modules to locate the user's vehicle easily. GPS module is used to track the location of the vehicle in the form of values such as latitude and longitude. These values are transmitted to the user using GSM modem through mobile network. Different sensors are used to detect alcohol consumption and to identify the accident. The Sensor values can be monitored by anyone from anywhere in the world using thingspeak channel. RFID technology is used to facilitate security to the vehicle tracking and anti-theft system. Ignition key is used to detect the theft and when theft is detected, GSM control app is used to control the vehicle remotely.
\end{abstract}

Keywords: Arduino, GPS, GSM, IoT,MQ3, RFID, Thingspeak.

\section{INTRODUCTION}

One of the most usable technologies in this trending world is IoT. IoT describes about the embedded devices which are interlinked with the internet. IoT Internet of Things encompasses devices like sensors, actuators, motors etc. Nowadays the major concern of the people is securing the valuable objects like vehicles. Security is enhanced by using GPS. The proposed system is used as an anti-theft system in transport systems, public vehicles.

GPS uses satellite technology to determine the location of the object. It finds the values in the form of latitude and longitude. Previously a two way GPS communication model was used to find the location of the lost vehicle but by using GSM modem it made easy to communicate in two ways which is cheaper and simple method.

There are many different methods or technologies which are used to control the vehicle when theft is identified. Some of the technologies are alarming system, password security, face reorganization, using RFID tags, etc. So, here in the proposed system theft is identified by using a ignition key and vehicle can be controlled by using GSM app remotely from anywhere. Different sensors are used to detect accident and alcohol percentage. Thingspeak channel uses Google cloud to store the sensors data. It allows visualizing and analysing the live data of the sensors. By using this data, automobile owner can monitor the sensors data graphically from anywhere in the world.

\section{RELATED WORK}

Many different technologies were used to control the vehicle when it is lost. Previously it was very difficult to determine the position of the automobile but now by using GPS technology it became very easy to track the position of the vehicle. A system is designed to note the location of the vehicle and to identify the theft by passing the information to the automobile owner. Such system includes GPS and GSM modules to determine the position of the vehicle and to deliver the information to the owner.

This system is designed for continuous monitoring of the vehicle and to describe the status of the vehicle on request [3].

Face recognisation system is used to identify theft. This face recognisation system will be placed inside the vehicle. When a person switches ON the vehicle, it captures the image and compares the new image with the stored image and verifies whether the image is already there in the list or not. If the image is not found in the list, the message will be sent to the automobile owner. Now the owner is allowed to see the image of the thief and location of the vehicle [4].

\section{PROPOSED SYSTEM}

This paper presents a system which is designed to trace the vehicle when it is lost using GPS and GSM technology. GPS receiver and GSM module uses Arduino UNO controller to forward the commands. This system is fixed inside a vehicle. GPS module will transfer the location values to the controller. Controller will receive it and sends that information to the automobile user using GSM modem. Now the owner can take appropriate action using GSM mobile App.

To provide security to the system which is placed inside car RFID technology is used. To monitor the sensors data a channel is used which is Thingspeak. This uses a IoT technology to store and visualize the sensors data. 


\section{A. Flow Diagram}

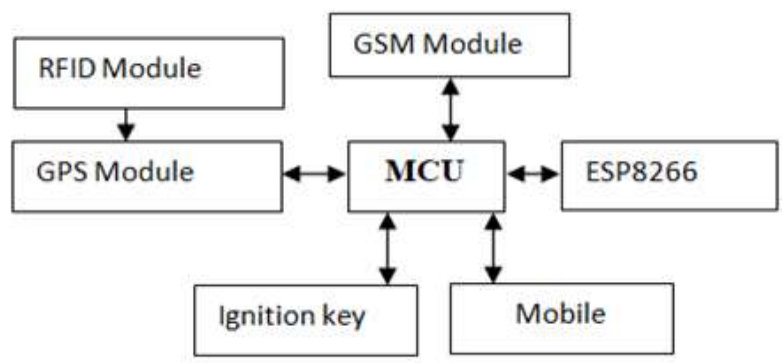

Figure: functional pattern of vehicle tracking system.

The above image shows a flow diagram of vehicle tracking system which is implemented using a GPS and GSM platform. It contains Arduino, GPS, GSM, RFID, sensors, ESP8266 modules.

\section{B) Interfacing Devices}

\section{i) ARDUINO UNO}

The main part of the vehicle tracking system is microcontroller. Arduino UNO is a open access microcontroller. Arduino controller board contains 16 input and output pins which are used to interfaced embedded devices. It works with a voltage of $5 \mathrm{v}$. it has a flash memory of $32 \mathrm{~KB}$ and static RAM of $2 \mathrm{~KB}$.

Arduino controller can be programmed in embedded $\mathrm{C}$ language in Arduino IDE.

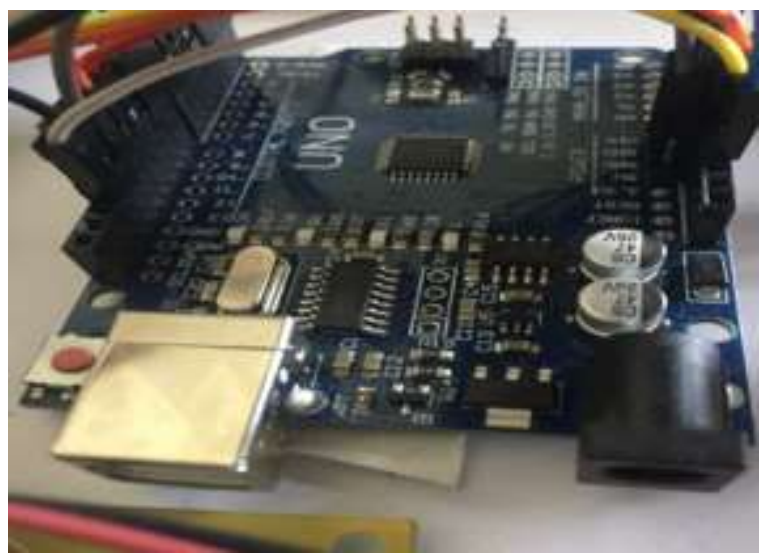

figure 2: ARDUINO UNO microcontroller.

\section{ii) Global Positioning System}

Global Positioning System uses a satellite technology to trace the signals. It works on the principle of 2D triliteration. When an object sends signals to the satellites, satellites resend the feedback signals back to the object. The time required to send the feedback signal is calculated to determine the geographical location of the object. GPS Tracking system uses Global Navigation Satellite System network to track the exact location of the vehicle. Vehicle tracking systems have been categorized into two types, passive and active system. Passive system monitors the location and stores the data whereas active tracking system monitors and sends information to a central tracking portal.

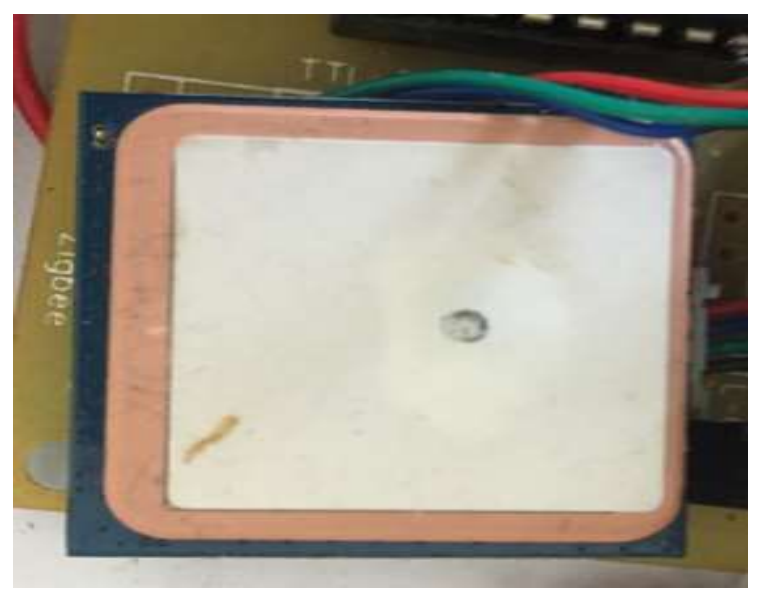

Figure: GPS module

It contains a serial port which is used to interface with the microcontroller. GPS Receiver sends the location data to the controller. Controller receives the data and transmits the data to the user using GSM.

\section{iii) Global System For Mobile Communication}

GSM is a serial communication device which is used to connect computer systems over a network. GSM module is interconnected with the microcontroller.

The receiver pin of microcontroller is wired with the transmitter pin of GSM modem and the transmitter pin of microcontroller is wired with the receiver pin of GSM modem.

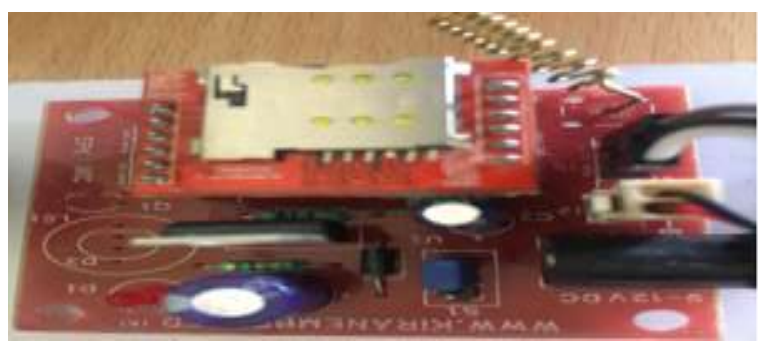

Figure: GSM modem.

It uses the attenuation commands to select the mode; to transfer and receive the messages, to call etc. it has an inbuilt SIM card holder which is used to insert the SIM for user operation. It uses time division multiple access technology.

The following are the few commands which are used:

\begin{tabular}{|l|l|}
\hline \multicolumn{1}{|c|}{ COMMAND } & \multicolumn{1}{c|}{ PUROSE } \\
\hline AT+CMGF & TEXT MODE \\
\hline AT+CMGS & SEND MESSAGE \\
\hline AT+CMGD & $\begin{array}{l}\text { DELETE } \\
\text { MESSAGE }\end{array}$ \\
\hline AT+CMGSS & $\begin{array}{l}\text { SEND STORED } \\
\text { MESSAGE }\end{array}$ \\
\hline AT+CMGA & $\begin{array}{l}\text { ANSWER THE } \\
\text { CALL }\end{array}$ \\
\hline
\end{tabular}




\section{iv) RFID Technology}

Radio-frequency identification works in electromagnetic field. RFID Technology uses radio frequency to scan the tags or objects. For automatic detection and data capture RFID technology is used. Passive tags can operate even at hundreds of meters. It does not require the object to be in line of sight.

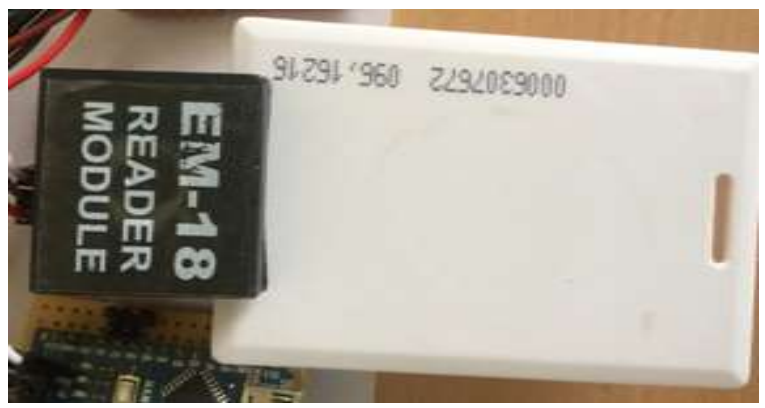

Figure: RFID reader and tags

RFID contains three parts: an incorporated circuit which is used to store the data and process the information which is further modulates and demodulates the radio frequency signals, power source and antenna.

This technology is used to provide security to the vehicle tracking system. By using the RFID tag only an authorized user can operate the vehicle tracking system.

\section{v) Thingspeak}

Thingspeak channel is correlated to the applications of IoT.Thingspeak is a platform which provides various services for the IoT applications. It allows real time data collection. The collected can be visualized in the form of charts. The data will be updated minute by minute. To create a channel first we need to signup, once we have a channel we can transmit the data and monitor it from anywhere in the world.

\section{METHODOLOGY}

GPS uses a tracking method to find the position of the lost vehicle interms of latitude and longitude values and it transfers that information using GSM module in the form of text SMS to the automobile owner.

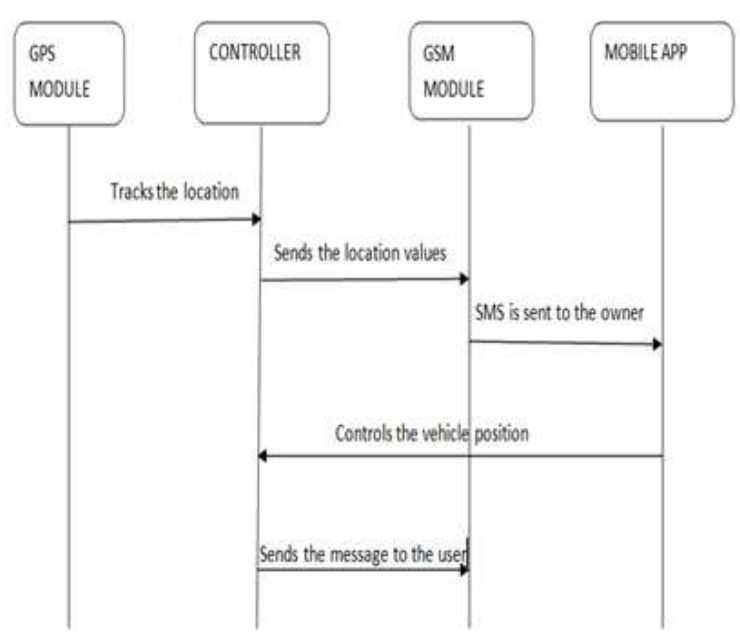

Figure: sequence diagram
Now the user can operate the vehicle remotely by sending the text messages to the GSM modem over a network using GSM App. Sensors are used to identify the alcohol consumption and accident detection. The automobile owner can know the position of the vehicle whenever he wants by sending the TRACK command.

If alcohol sensor or accident detection sensor is activated the owner gets the message and the sensors data will be updated in the thingspeak channel.

\section{RESULTS}

Initially when ignition key is $\mathrm{ON}$ it intimates the automobile owner as vehicle theft. If the vehicle is driven by unknown person, the automobile owner blocks the vehicle by sending BLOCK command.

\section{A) When ignition key is $O N$ :}

When ignition key is in active mode the user gets message, generally if car is driven by owner he uses ignition key to run the vehicle and he ignores the message. If the car is driven by an unauthorised person, the automobile owner gets the message and he should take an appropriate action. To identify the theft we are using ignition key in this proposed system. Now the owner uses a mobile app and sends message to block the vehicle.

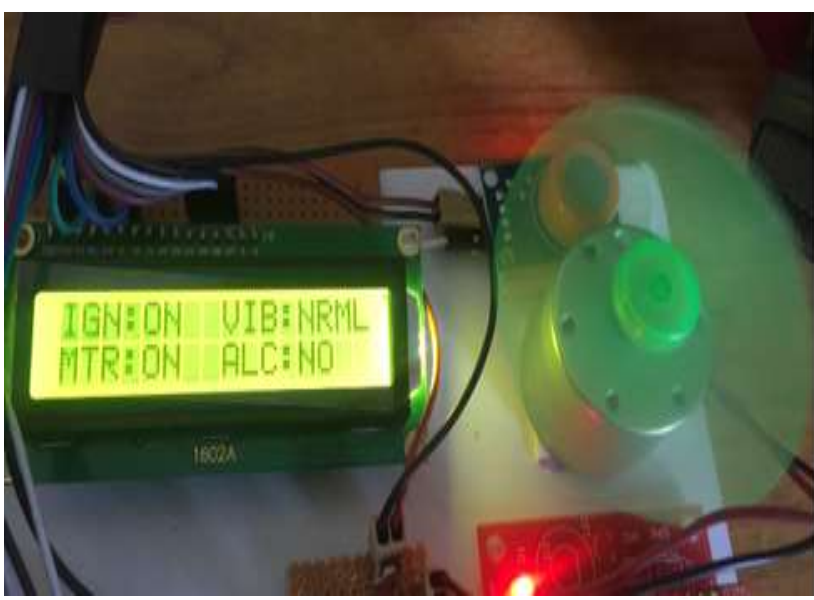

\section{Vehicle Monitoring System IGNITION ON}

Fig5.1: when vehicle is in ignition mode.

\section{B) When vehicle is blocked}

When the vehicle is driven by an unauthorised person the user gets the message. Now the user controls the vehicle remotely by sending the message using GSM app. Using this App reduces the time consumption to send the message. When the user sends the message as block it blocks the vehicle and vehicle stops there. 


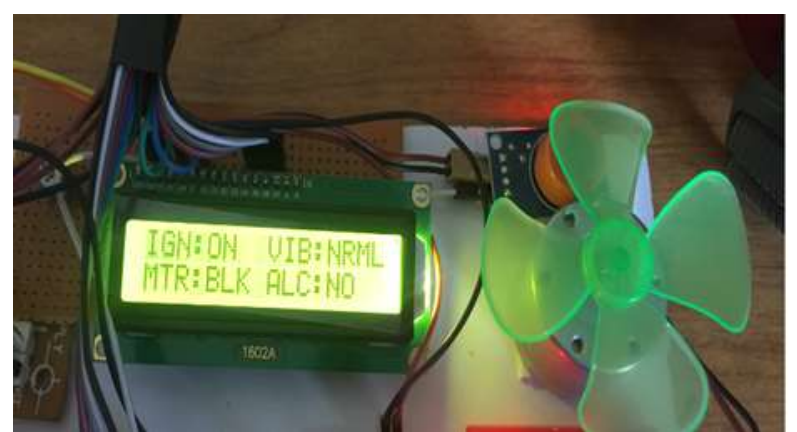

Fig: when vehicle is in BLOCK mode

C) When we want to track the vehicle:

After blocking the vehicle to find the location of the vehicle exactly where it has been stopped, owner has to send track message. The owner gets the location with latitude and longitude values and points out on the Google map. Until and unless the owner sends the start message the vehicle will not start, it will be in block mode.

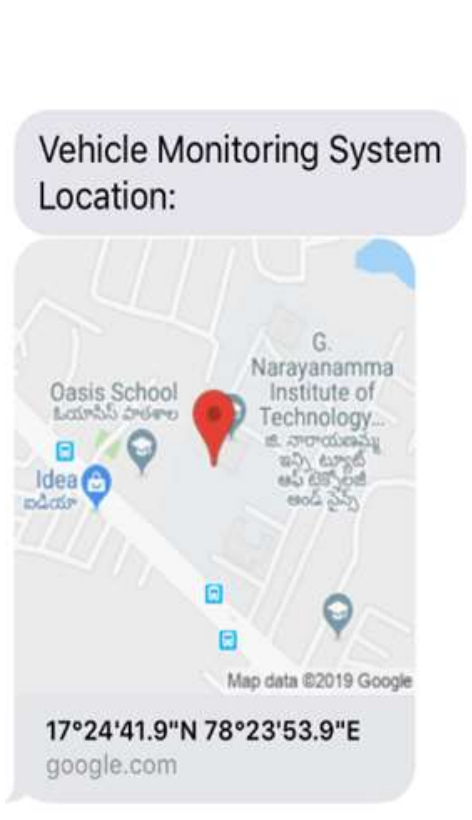

D) When sensors are in active mode:

Here we are using two sensors one is alcohol sensor to detect alcohol content and the other one is piezoelectric sensor to detect collision or accident. When alcohol sensor is in active mode, the controller sends the message to the automobile owner and updates the data into the thingspeak channel.

When accident is occurred the respective sensor will be in active mode. When it is in active mode the owner gets the message with location values and automatically the vehicle stops. Unless and until the owner sends a start message the vehicle will not move.

Vehicle Monitoring System
Location:
https://www.google.com/maps/.
place/17+22.07886N,
$078+26.78994 \mathrm{E}$
Accident Detection

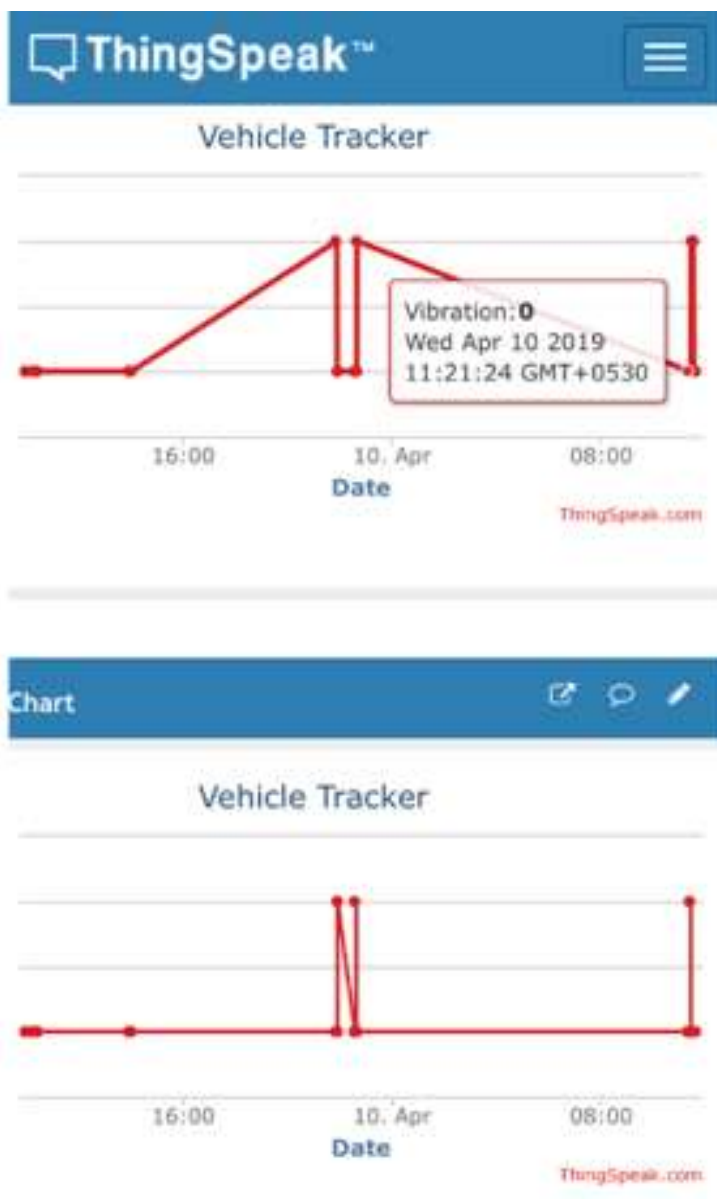

Fig: sensors 'details in thingspeak channel.

The sensors data will be stored in Google cloud. First we should open the thingspeak and login by giving the credentials like login ID and password. Select the required number of fields. When we enter into the channel we get the API key by using which we can send the sensors data to the cloud. We can monitor the sensors from anywhere in the world. First provide wifi SSID name and password in the program to get connected with the internet. The sensors data will be updated every minute.

\section{CONCLUSION}

The most essential thing in today's world is providing security to the public and private vehicles. So, vehicle tracking system is proposed to locate the exact position of the vehicle when it is lost or hidden somewhere. GPS technology is used to track the location and that data is transmitted to the user using GSM. Along with the tracking system anti-theft system is also developed to provide security. It is mostly applicable in fleet management, transportation system, military applications, school buses, public vehicles etc.

\section{FUTURE SCOPE}

Further this system can be enhanced into the advanced system which uses IoT concept to operate the vehicle remotely by anyone from anywhere in the world. It can be arranged in such a way that it can connect a call to the owner or it can send the information to the multiple persons.

\section{Published By:}

Blue Eyes Intelligence Engineering 


\section{REFERENCES}

1. H. D. Pham, M. Drieberg and C. C. Nguyen, "Development of vehicle tracking system using GPS and GSM modem," in IEEE Conference on Open Systems (ICOS), Kuching , 2013.

2. Mashood Mukhtar, "GPS based Advanced Vehicle Tracking and Vehicle Control System", I.J. Intelligent Systems and Applications, 2015, 03, 1-12

3. Albert Alexe, R. Ezhilarasie, "Cloud Computing Based Vehicle Tracking Information Systems", ISSN: 2229 4333 (Print) | ISSN: 0976 - 8491 (Online) IJCST Vol. 2, Issue 1, March 2011

4. Ambade Shruti Dinkar and S.A Shaikh, Design and Implementation Of Vehicle Tracking System Using GPS, Journal of Information Engineering and Applications, ISSN 2224-5758, Vol 1,No.3, 2011.

5. M. Ahmad Fuad and M. Drieberg, "Remote vehicle tracking system using GSM Modem and Google map," in IEEE Conference on Sustainable Utilization and Development in Engineering and Technology (CSUDET), Selangor, 2013.

6. M. Parvez, K. Ahmed, Q. Mahfuz and M. Rahman, "A theoretical model of GSM network based vehicle tracking system," in International Conference on Electrical and Computer Engineering (ICECE), Dhaka, 2010.

7. R.Ramani,S.Valarmathy,D. N.SuthanthiraVanitha, S.Selvaraju and M.Thiruppathi.R.Thangam,"Vehicle Tracking and Locking System Based on GSM and GPS," I.J. Intelligent Systems and Applications, vol. 09, pp. 89-93, August 2013.

8. P. P. Wankhade and P. S. Dahad, "Real Time Vehicle Locking and Tracking System using GSM and GPS Technology-An Anti-theft System," International Journal of Technology And Engineering System, vol. 2,no. 3, 2011.

9. P. Verma and J. Bhatia, "Design and Development of GPSGSM based Tracking System with Googlemap based Monitoring," International Journal of Computer Science, Engineering and Applications (IJCSEA), vol. 3, no. 2,June 2013.

10. N Mangla, K Sushma, L Kumble," IPB-Implementation of Parallel Mining for Big Data", Indian Journal of Science and Technology, 2016

11. T. Le-Tien and V. Phung-The, "Routing and Tracking System for Mobile Vehicles in Large Area," Fifth IEEE International Symposium on Electronic Design, Test and Application, pp. 297-300, January 2010.

12. P. Fleischer, A. Nelson, R. Sowah and A. Bremang, "Design and development of GPS/GSM based vehicle tracking and alert system for commercial inter-city buses," IEEE 4th International Conference on Adaptive Science \& Technology (ICAST), October 2012. 